\title{
Influence of the volute design parameters on the flow phenomena and performance of the centrifugal compressor
}

\section{Haitham M Hadidi, Mohammed Y. Tharwan, and Ahmed S. Hassan}

Department of Mechanical Engineering, College of Engineering, Jazan University, P. O. Box 706, Jazan 45142, Kingdom of Saudi Arabia E-mail address: haitham.hadidi1@gmail.com ashassan7@yahoo.com

\begin{abstract}
Influence of the volute design parameters on the stable operating range and the performance of a centrifugal compressor was investigated experimentally for the following design conditions. The volute casing surface roughness was changed from 0 to $200 \mu \mathrm{m}$ in five steps and tested. The axial distance between the casing and the diffuser cascades (clearance) was varied in five steps as $C / b_{2}=1.2$, $2.4 \%, 3.6 \%, 4.8 \%$, and $6 \%$ relative to the impeller exit width. The radial distance from the impeller blade exit to the diffuser vane inlet in (vaneless space radius) in six steps as $C / r_{2}=1.03,1.05,1.07$, $1.09,1.11$, and 1.13 relatives to the rotor outlet radius. The volute outlet geometry of a symmetric and tangent with different area ratios from 0.4 to 0.9 . Finally, the compressor has been tested experimentally with different pinched vaned diffuser distances relative to the impeller exit width of $\mathrm{bp} / \mathrm{b2}=1,0.98,0.96,0.94,0.92$, and 0.9.

These testes were carried at different compressor operating conditions, and the time variations of the static pressure were recorded using five high-frequency response pressure transducers. A hotwire anemometer is used to measure the compressor flow rate. The rotating stall and surge at the vaneless zone after the impeller exit can be detected by analyzing the fluctuations of pressure signals and the power spectrum density by using the Fast Fourier Transformation analysis. The experimental results indicated that the compressor with volute casing surface roughness of $100 \mu$ m gives about 10.9\% enhancements in the stable operating and $1 \%$ in pressure rise coefficient. The best axial distance between the diffuser vanes and the casing is $2.4 \%$ of the impeller blade height and the compressor in this design gives about $12.4 \%$ improvements in the stable working range. The compressor with radial vaneless distance of 1.056 gives improvements of about 16.6\% in the surge margin, $2 \%$ in the pressure recovery and $4 \%$ in pressure rise coefficients. The compressor with a pinched diffuser of b/bp of 0.98 gives an improvement of $20.8 \%$ in surge point.
\end{abstract}

Key words: Casing treatment; Surge margin; Rotating stall; surface roughness; flow instability

\begin{tabular}{|ll|ll|}
\hline Nomenclature: & $\mathrm{Q}$ & Volume flow coefficient, $\mathrm{m}^{3}$ \\
$\mathrm{~b}$ & Width at vaneless zone, $\mathrm{mm}$ & $\mathrm{r}_{2}$ & Impeller exit radius, $\mathrm{mm}$ \\
$\mathrm{b}_{2}$ & Widths of impeller exit, diffuser, $\mathrm{mm}$ & $\mathrm{r}_{\mathrm{v}}$ & Radius of vane diffuser, $\mathrm{mm}$ \\
$\mathrm{b}_{\mathrm{p}}$ & Pinched diffuser width, $\mathrm{mm}$ & $\mathrm{U}_{2}$ & Impeller tip speed, $\mathrm{m} / \mathrm{s}$ \\
$\mathrm{C}$ & Axial clearance, $\mathrm{mm}$ & $\rho$ & Density, $\mathrm{kg} / \mathrm{m}^{3}$ \\
$\mathrm{P}$ & Pressure, Pa & $\Phi$ & Flow coefficient $=\mathrm{Q} / 2 \pi \mathrm{b}_{2} \mathrm{r}_{2} \mathrm{U}_{2}$, \\
$\Delta \mathrm{P}$ & Difference bet. comp. inlet and exit, $\mathrm{Pa}$ & $\Psi$ & Pressure coefficient $=2 \Delta \mathrm{P} / \mathrm{\rho U}_{2}{ }^{2}$. \\
\hline
\end{tabular}




\section{Introduction and literature review}

Centrifugal compressors are used in many applications such as turbochargers for vehicles, aircraft, power plants, helicopters, process industries, compressing gases, and vapors because they offer high-pressure ratios and large operating ranges with relatively high efficiency. Also, the centrifugal compressors have advantages over axial compressors, such as higher pressure ratio, lower weight, and ease of assembly. Therefore, the demand from companies that manufacture cars is increasing, which challenges manufacturers to improve the compression ratio, efficiency and increase the stable operating range [1-3]. Improving the specifications of the turbocharger compressor requires an increase in the compression ratio while maintaining the operating range of the panel, thus increasing the engine power production, reducing noise and air pollutants, and thus reducing the overall size of the machine, and increasing its efficiency [4]. One way to increase the range of stable flow is to use surface roughness as a method of passive flow control $[5,6]$. Two types of unstable flow occur in the centrifugal compressor, those are rotating stall and surge. The rotating stall is a phenomenon that occurs at a reduced flow rate due to flow separation and occurs before increased flow transport in the direction of the rotating impeller [7]. When the stall divides into many stalled cells, it propagates in a circumferential direction at a speed less than the speed of rotation of the impeller [8]. As the mass flow rate decreases near the stall point, the high angle of incidence at the impeller exit produces flow recirculation and flow separation that leads to surge [9]. The surge is an aerodynamic instability in the compressor that causes intermittent reversal of gas flow throughout the compressor due to the opposite pressure gradient [10]. One method to prevent flow separation in the impeller and the seismic-free zone, the casing surface roughness was increased to control the stall [11]. These impeller components contribute to the maximum entropy generation but impart greater sensitivity to deflection in surface roughness [12]. Surface roughness affects the flow structure of compressors and turbines. Based on general trends, it is still far from our ability to accurately predict the effects of roughness on losses due to fluid friction and surface heat transfer [6]. The roughness characterization of equivalent sand grains (ks) has hampered the comprehensive use of the modeling because it does not take into account the effects of different roughness on heat transfer, skin friction, and boundary layer transmission [13]. A study on the effect of the surface roughness of the impeller shows that it is a global model for stopping the turbulent flow near the wall [14].

Numerically [15] studied the effect of the radial gap between the impeller trailing edge and the diffuser vanes leading edge on the compressor performance and concluded that increasing the ratio of the radial gap decreases the slip and increases the loss. Jaatinen et al. [16] also mentioned that the radial gap ratio has an ideal value and if the radial gap ratio is less than this value, the harm of increased loss will exceed the benefit of reduced slip and blockage. Theoretical analysis was made [17] on a highpressure ratio centrifugal compressor has slotted in the diffuser passages, and the results show that when the mass flow rate decreased, there is flow separation at the angle of the distributor axis, which was eliminated by the slag of the slot length, which was $8-16 \%$ of the diffuser chord length, thus increasing the stable flow rate without a significant decrease in the compressor performance. The increasing tip clearance causes additional losses and lowers compressor stage efficiency, especially at higher mass flows $[18,19]$. On the other hand, Japikse [20] studied the pressure recovery and the loss coefficients of three volutes with different area ratios. Several numerical and experimental studies have been performed for overhung volutes with an elliptical, rectangular or circular cross section [21,22]. Because the diffuser inlet flow was significantly affected by the upstream impeller outlet flow, so reduced tip clearance gives a more uniform flow at the impeller exit [23] and improves diffusion processes inside the vaneless diffuser. The aforementioned research showed some modifications to the design of the spiral casing in order to improve the compression ratio and efficiency of the centrifugal compressor. But, there is no 
previous detail to show the effect of spiral casing design on compressor flow stability such as stall start, impulse suppression, and stable operating range. However, they did not report any effect of the pinch on improving the increased line. The current work examines the effect of each of the following on the compressor stable working range and pressure coefficient: casing surface roughness, change the clearance between the casing and the diffuser vanes; the pinched diffuser with different pinched vaned diffuser distances relative to the impeller exit width of $\mathrm{bp} / \mathrm{b}_{2}=1,0.98,0.96,0.94,0.92$, and 0 .

\section{Experimental Work}

To illustrate the influence of volute design parameters such as surface roughness, clearance between the diffuser blade and casing, volute geometry, on the compressor range of stable operation and performance a complete test facility was installed. This test rig consists of a centrifugal compressor of radial blade impeller, parabolic vanes diffuser, and volute casing which is driven by a $5 \mathrm{~kW}$ variable speed motor. This centrifugal compressor has been taken from an aircraft's turbocharged engine. It draws the air from the atmospheric conditions into a large tank which is followed by an orifice flow meter device and control valve to measure and control the flow rate. Three pressure transducers are incorporated into the compressor casing, and two are jointed into the vaneless region with a 90-degrees shift through the circumference at the same radius. The pressure transducers are from types of highsensitivity semiconductors, omega, PX-236-100GV silicon diaphragm with a full bridge. A DC amplifier that receives the output signals from the pressure transducers provides a 16-bit A/D converter board supported into PC-SCOPE software into simultaneous pressures for one second at a rate of one $\mathrm{kHz}$. The board is supported by PC-SCOPE software. It turns the computer into an oscilloscope and stores the pressure waveforms in ASCII files. Then the data in the file is processed using the Fast Fourier Transformation Analysis (FFT) to estimate the Power Spectrum Density (PSD) by plotting the modified and averaged periodicity of the time-discrete signal vector. The surge point can be obtained using pressure spectrum (analyzing the pressure downstream of the compressor), the frequency peak which describes the surge was between 18 and $22 \mathrm{~Hz}$ [17]. Where $\Phi$ is flow coefficient $=\mathrm{Q} / 2 \pi \mathrm{b}_{2} \mathrm{r}_{2} \mathrm{U}_{2}, \Psi$ is the pressure coefficient $=2 \Delta \mathrm{P} / \rho_{U_{2}}{ }^{2}$.

Figure 1 shows the compressor pressure coefficient against flow coefficient during stable and present rotating stall and surge. At the compressor operating point A, where, $\Phi=0.271$, the compressor runs stably because the amplitude of pressure fluctuations and the corresponding power spectrum density (PSD) at the diffuser inlet are very-small levels. When the compressor operates at the flow coefficient $\Phi=0.115$ (point - B), the amplitude of pressure fluctuations reaches about $20 \%$ of the compressor's maximum pressure coefficient with a frequency of $17 \mathrm{~Hz}$, where the compressor runs in the presence of a rotating stall. As the compressor operates at a lower flow rate, $\Phi=0.097$ (point - C), the amplitude of pressure fluctuations reaches about $35 \%$ of the compressor's maximum pressure coefficient with a predominant surge frequency of $8 \mathrm{~Hz}$. The previous method was used in all the different design cases with the compressor to determine the beginnings of the rotating stall and surge.

\subsection{Effect of volute surface roughness on the compressor flow stability and pressure coefficient}

In the previous part of the present work, the method for determining the mass flow rates at which the initiation of the rotating stall and surge using the previously mentioned analyzes according to the previous figure for the compressor performance with smooth casing was used. The objective of this part of the research is to investigate the effect of the surface roughness of the volute casing from the smooth to $200 \mu \mathrm{m}$ on the stable working range and the equivalent pressure of the compressor. It should be noted here that according to the reference note [8], the surface of a smooth metal usually has a roughness of about $3.18 \mu \mathrm{m}$. 


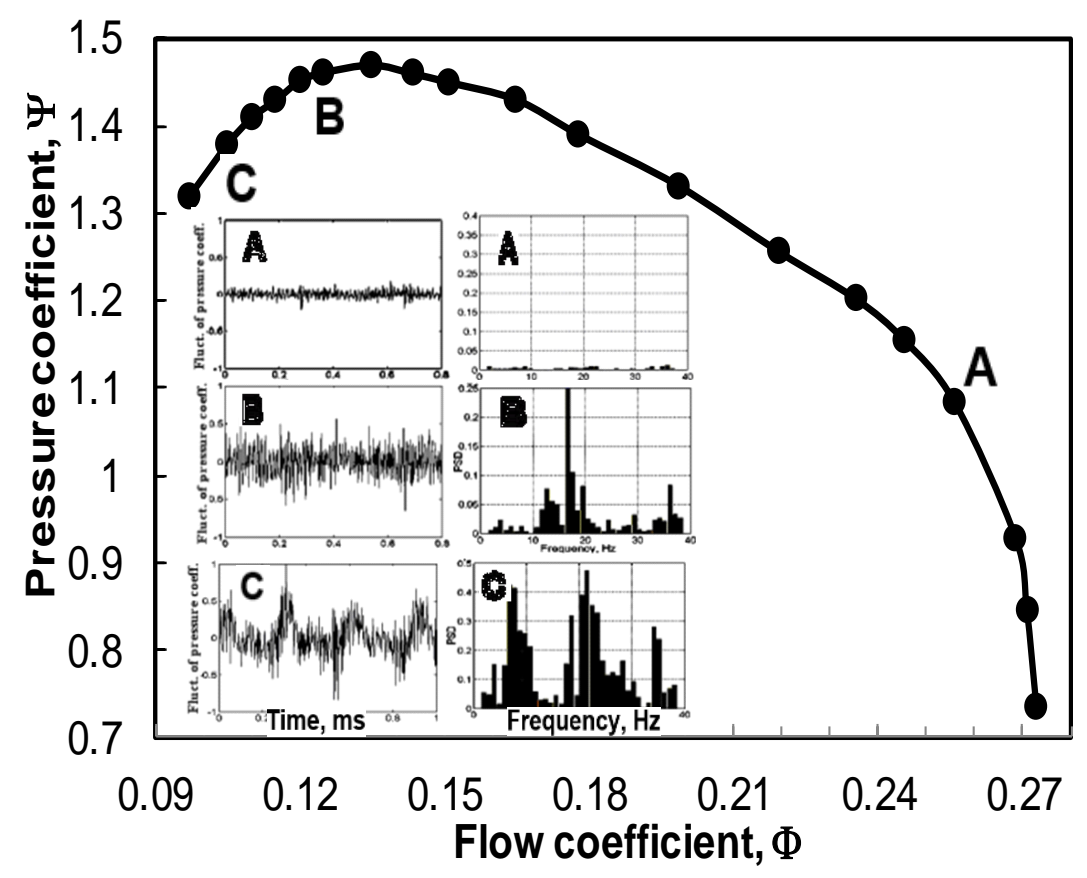

Fig. 1: Compressor performance during stable operation and present of rotating stall and surge.

In applications with a high Reynolds number, the effect of surface roughness is used to increase the transition velocity of the laminar-turbulent separation and delay the flow. Therefore, to reduce the flow recirculation at the rotor exit, the volute casing surface roughness was changed from 3.7 to $200 \mu \mathrm{m}$. Figure 2 shows the effect of volute surface roughness on the stable flow range and pressure coefficient of the centrifugal compressor of a turbocharger. The figure shows the relationship between the pressure and the flow rate of the compressor with different surface roughness from 7 to $200 \mu \mathrm{m}$. It is clear from the figure that the rate of behavior in which the compressor is unstable due to the occurrence of vortices or serge decreases with the increase in the surface roughness of the casing to the surface roughness of 100 and then the effect decreases somewhat. As well as the same phenomenon of high pressure. This proves that the best design for the compressor casing is to have a surface roughness of $100 \mu \mathrm{m}$ because it disrupts the stability of the compressor's work as well as the pressure. And increasing the volute surface roughness than 100 leads to decrease in the range of compressor stable flow range and the pressure coefficient.

Figure 3 shows increases of the pressure coefficient by increases of the surface roughness from 0 to $100 \mu \mathrm{m}$ due to increasing the coefficient of friction between the casing and the liquid. This confirms that the increase in the surface roughness of the casing from smooth to $100 \mu \mathrm{m}$ leads to the possibility of operating the compressor at low flow rates as a result of stopping the formation of vortices in the area free of decorations, and thus the failure to stop. Also in the case of surface roughness of 100 and $150 \mu \mathrm{m}$, a significant improvement in the stable working range of the compressor was observed. This confirms that increasing the flute surface roughness reduces the flux separation on the surface of the diffuser shroud. The upper curve in Fig.3 shows the peak pressure factor of the compressor versus the helical surface roughness and its significant impact on compressor performance. The most significant drop in pressure ratio was observed when roughness magnitude rose to $200 \mu \mathrm{m}$. The drop in pressure ratio has started when the roughness magnitude has been incrementally increased from $150 \mu \mathrm{m}$ to $200 \mu \mathrm{m}$ as shown in Figure 3. 


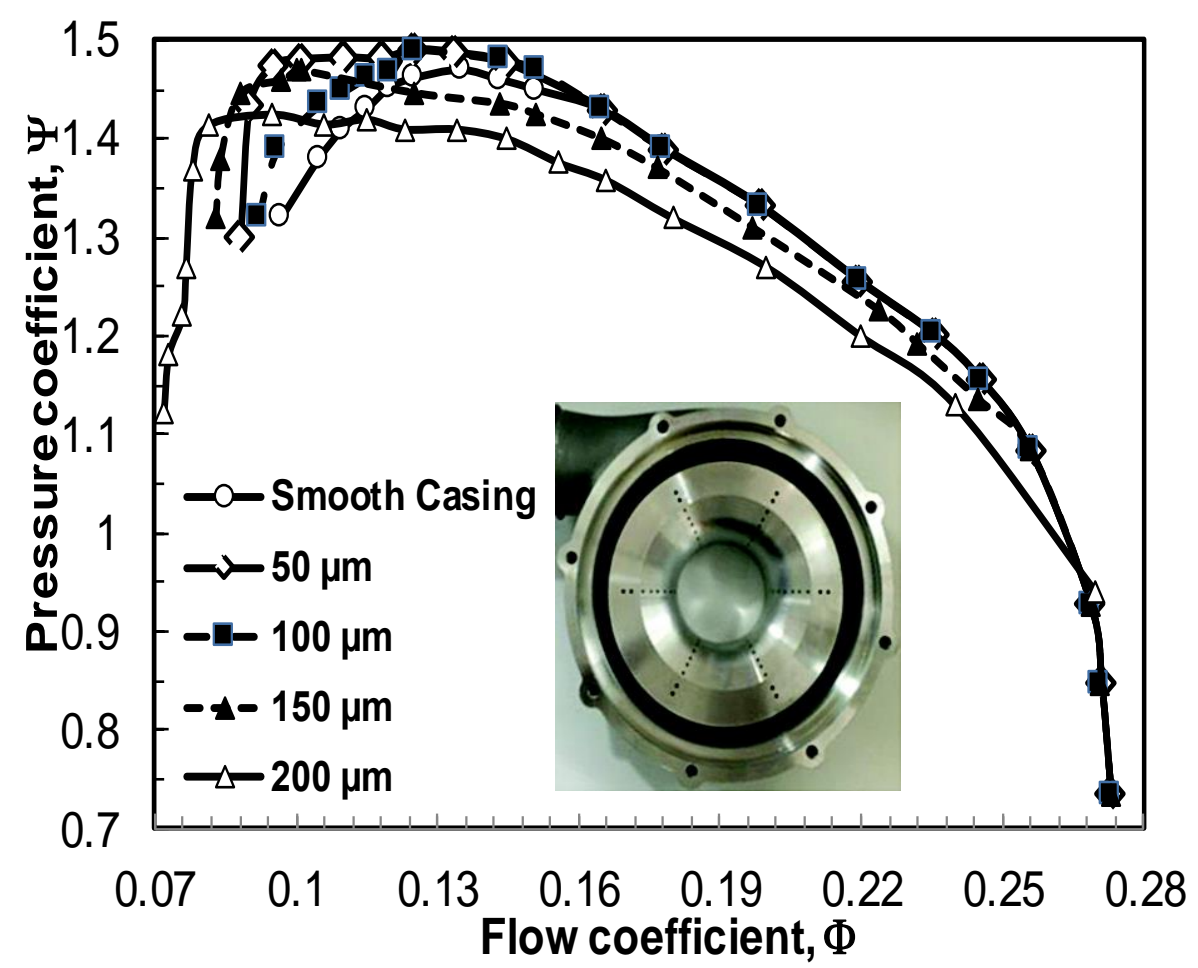

Fig.2: Effect of surface roughness on the compressor performance

This loss in the pressure ratio is attributed to the frictional losses and thick boundary layer in the diffuser section and leads to an increase in surface blockage. The application of surface roughness of $100 \mu \mathrm{m}$ increased the operating range of surge by about $10.9 \%$, and stall margin increased by about $11.2 \%$ due to controlling flow separation and flow recirculation effects.

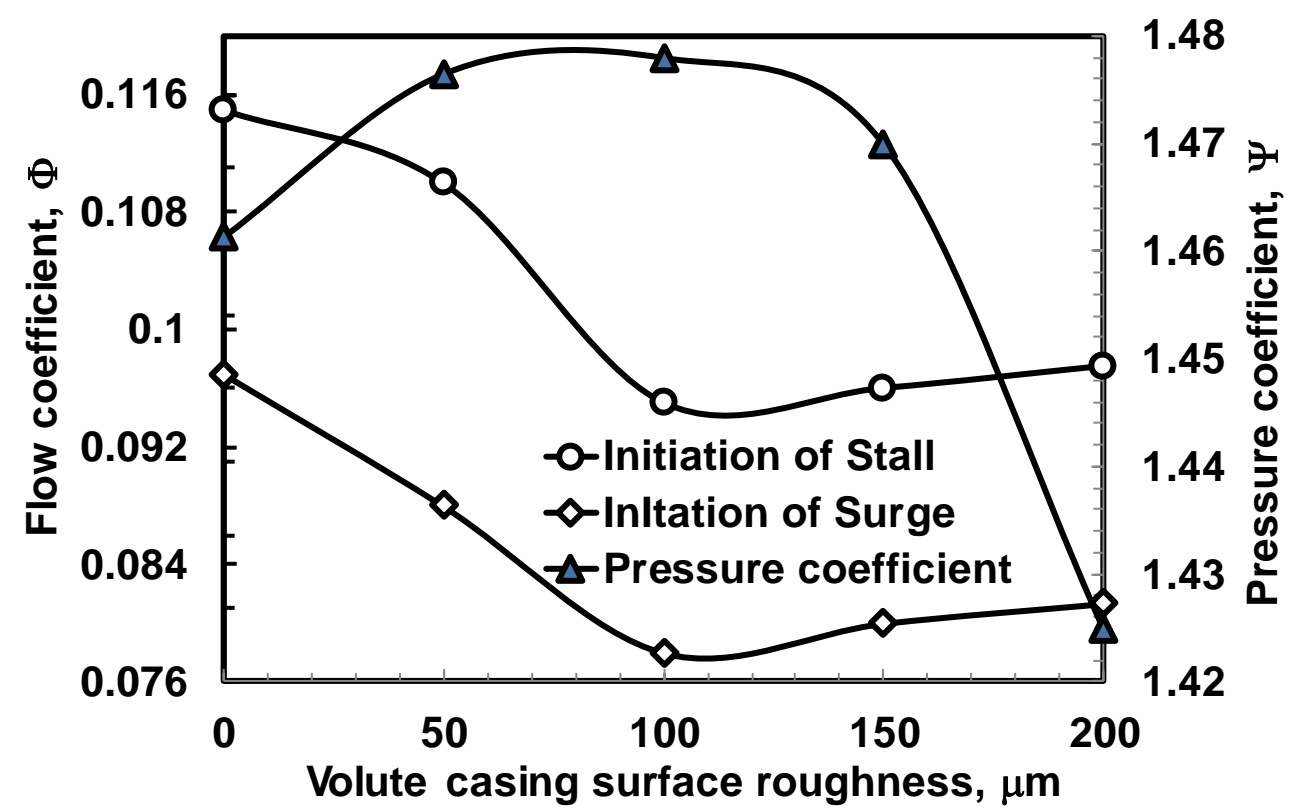

Fig.3: Effect of surface roughness on the compressor pressure coefficient, and stall and surge initiation 


\subsection{Effect of the axial clearance between casing and diffuser on the compressor performance}

Flow leakage, vortices, separation, loss, fluid recirculation, or rotary stall within or between centrifugal compressor elements is mainly the cause of performance deterioration and the narrowing of the stable flow range due to a lack of careful design of the impinging distance or clearance between Rotary element and casing. In the present paper, experiments were carried out to determine the effect of the axial clearance between the diffuser vanes and the casing on the compressor performance and the flow phenomena. The axial clearances were changed, $\left(\mathrm{c} / \mathrm{b}_{2}\right)$ from $1.2 \%$ to $6 \%$ of the impeller exit blade height with an increase of $2.4 \%$ in each case. Where is the axial distance between the casing and impeller blade tip at the exit, and b2 is the height of the impeller blade exit height. Figure 4 shows the effects of the clearance on the compressor pressure coefficients and stable flow range due to rotating stall initiation and surge triggering. The previous figures show that increasing the clearance ratio has decreased the pressure coefficient at the low flow rates due to the separation of the boundary layer of the sidewall from the wall due to the sharp gradient of the radial pressure. But at the small clearance between the impeller and the casing, the compressor pressure coefficient increases due to increasing the pressure recovery coefficient with the decrease in the flow rate, and the diffuser proves the characteristic curve of the compressor.

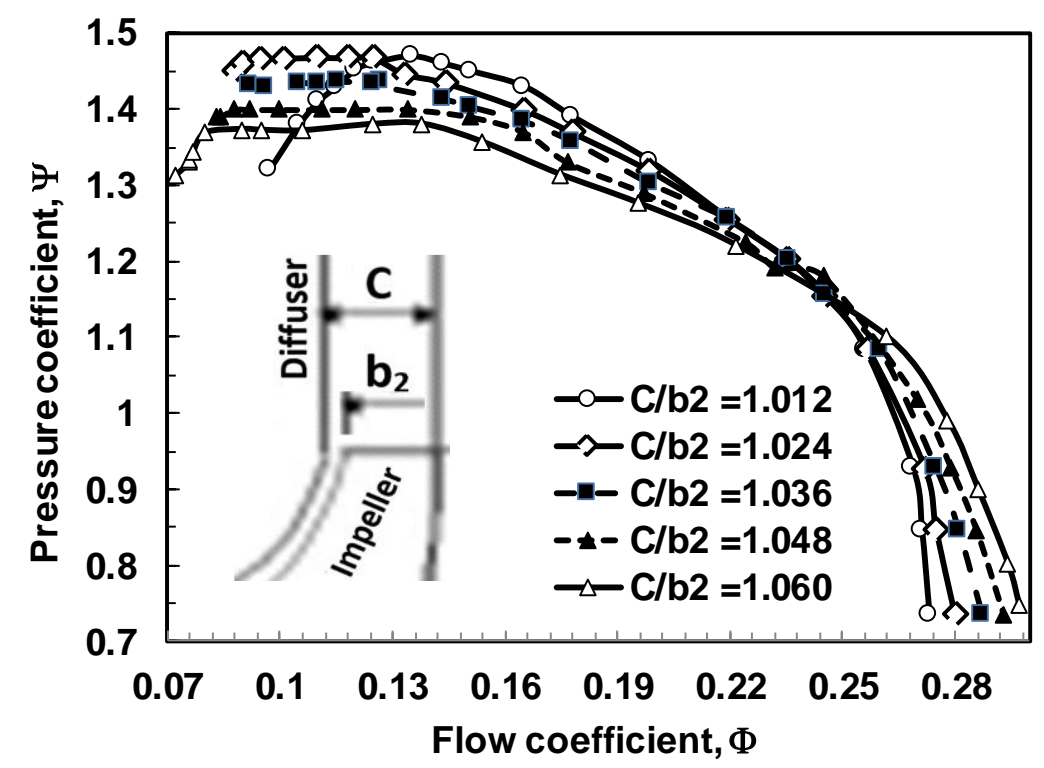

Fig.4: Effect of axial distance or clearance, c/b2 on the compressor performance

Figure 5 represents the flow coefficient of initiation of the rotating stall, surge, maximum flow (chocking), and pressure rise coefficient at different clearance ratios. It is clear from the figure that increases the compressor maximum flow rate or chocking mass flow, decreases the pressure coefficient, and decreases the mass flow rate of unstable conditions due to the initiation of the rotating stall and the surge. The figure indicated that the compressor with the axial clearance equal to $4 \%$ gives maximum values of the stable operating range relative to other different clearance ratios. This figure summarizes that the best design of the axial distance or clearance between the diffuser vanes and the casing is $2.4 \%$ of the impeller blade height. The centrifugal compressor in this design gave about a $10 \%$ improvement in the working range of the surge and about $12.4 \%$ improvement in the stable working range in respect to the chock to the surge. This means that the compressor design at a clearance ratio of $2.4 \%$ from the peak of the impeller blades exit prevented the flow from separation and its wisdom in not forming vortices at the low flow rate, thus suppressing the occurrence of reverse flow or triggering the surge. 


\subsection{Effect of the radial distance between impeller blade exit and diffuser vane inlet}

The effect of changing the radial space from the impeller exit to the vaned diffuser inlet on the centrifugal compressor performance characteristics and flow phenomenon is investigated and presented in Fig.6. The radial distance was changed in six steps of, $r_{v} / r_{2}=1.03,1.05,1.07,1.09,1.11$, and 1.13. The results show that reducing the radial clearance ratio decreases the compressor's maximum flow rate (choking). Figure 6 shows the pressure coefficient at low flow rate increases with the increase in the radial distance. Also, the mass flow coefficient at the surge as well as stall initiation decreases as the radial distance ratio increases due to interaction between the impeller and diffuser.

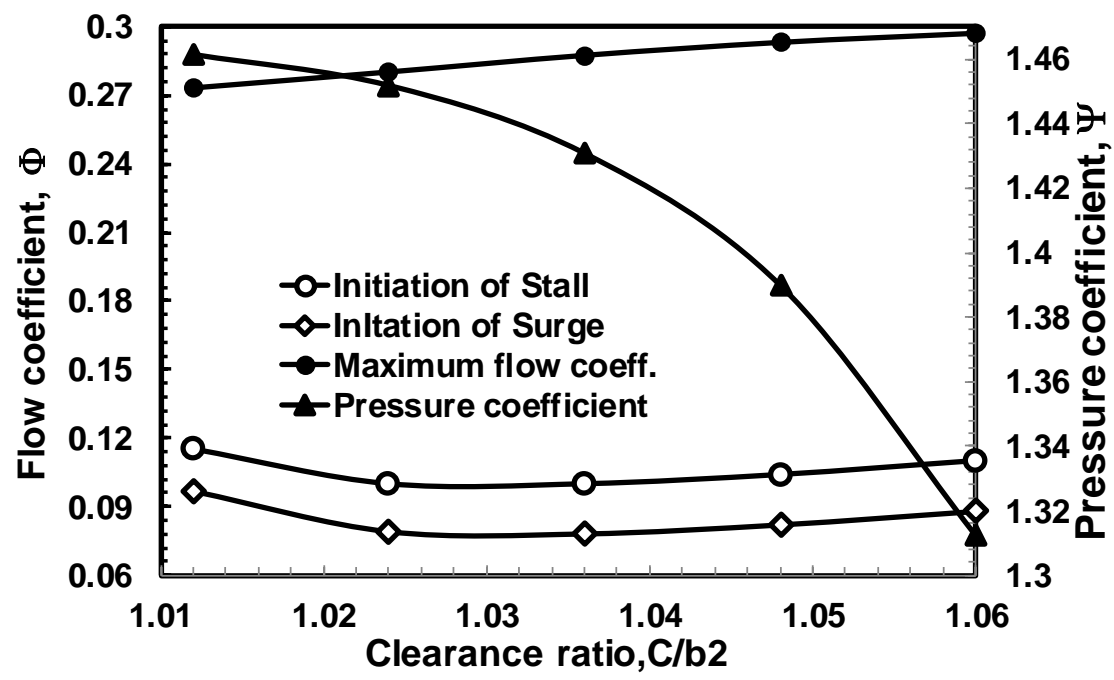

Fig.5: Effect of axial distance, $\mathrm{c} / \mathrm{b}_{2}$ on the pressure coefficient, mass of chocking, stall and surge

It seems from Fig.6 that increasing the radial gap between the rotating impeller and the stationary diffuser decreases the stable operating range of the compressor due to an increase of the flow separation at the vaneless region. Figure 7 shows there is the best design for the surge trigger. That is the improvements in the compressor range of stable operation for the different radial distances between the impeller blade exit and diffuser vanes inlet ratios are due to the decrease of the flow recirculation in the impeller. Figure 7 show the compressor with a radial distance ratio of 1.057 gives the best performance. The compressor with the radial vaneless distance of 1.056 gives improvements of about $16.6 \%$ in the surge margin, $2 \%$ in the pressure recovery, and $4 \%$ in pressure rise coefficients. That is decreasing the radial distance between the impeller exit and diffuser vanes inlet lowered the loss, reduces the wake region, and improved diffusion inside the vaneless region. The present laboratory results are in good agreement with the published theoretical results of Swamy et al. [23], despite the difference in compressor dimensions.

\subsection{Effect of pinched diffuser on compressor performance}

The compressor has been tested experimentally with different pinched vaned diffuser distances relative to the impeller exit width of $\mathrm{bp} / \mathrm{b}_{2}=1,0.98,0.96,0.94,0.92$, and 0.9 and the results are illustrated in Fig. 8. The pressure rise coefficient and the maximum mass flow (chocking) decrease as the pinched ratio increases at the higher flow coefficients. While the compressor pressure rise coefficient increases as the pinched increases at low flow rates. It is very clear in the figure that the range of stable mass flow rate of the compressor increases as the pinched diffuser depth increases. 


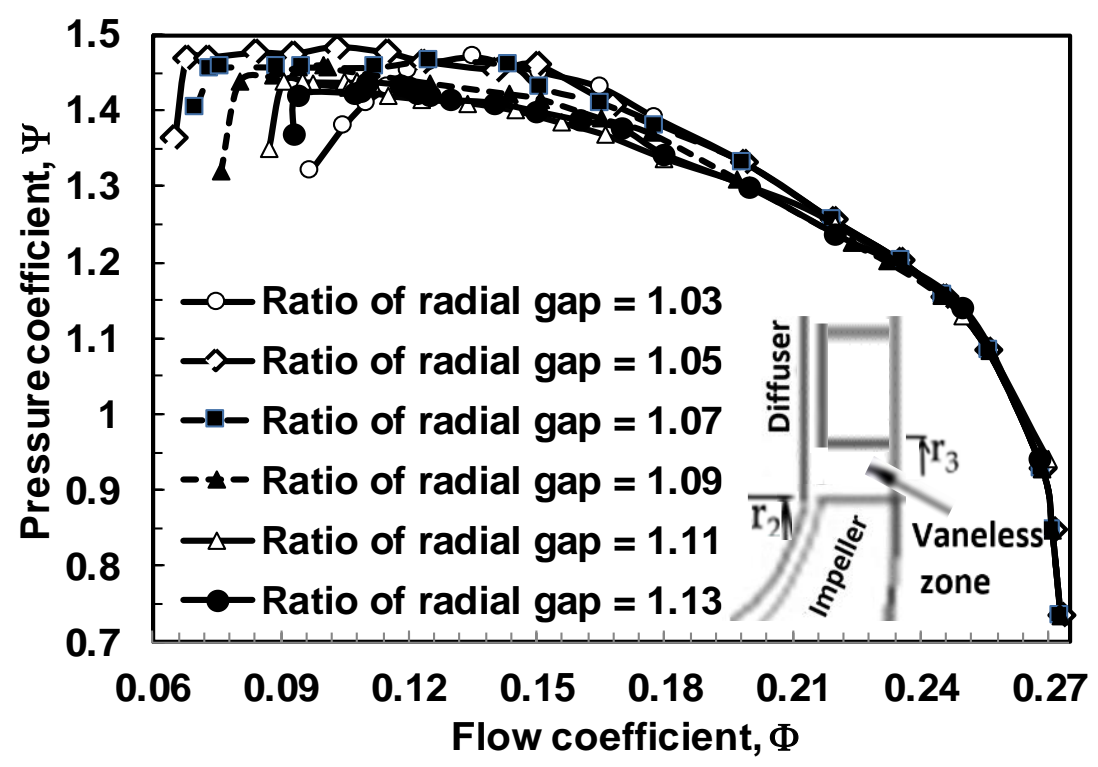

Fig.6: Effect of changing the radial space on compressor performance

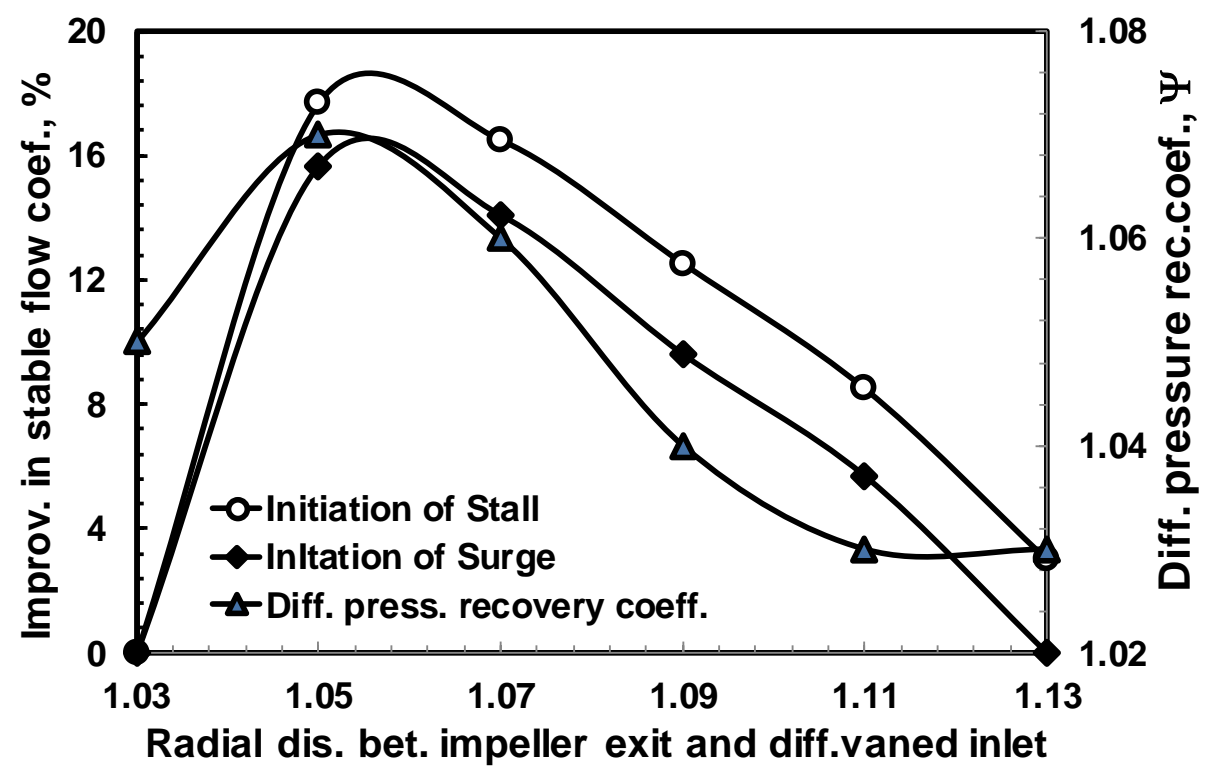

Fig.7: Effect of the radial distance on the compressor performance

In all laboratory results in this research, the fluctuations of the pressure rise coefficients against the time in milliseconds (ms) are recorded, analyzed using the power spectrum density as previously mentioned, and used as a straw to know when the compressor instabilities due to rotating stall and surge occurred. Figure 9 is an example, which shows the pressure fluctuation at different flow rates from the compressor maximum flow rate to the lowest possible flow rate. Only a sample of the two different designs of pinched diffuser ratio, b/bp of 1 and 0.98 , are shown in the figure which show how the design of the diffuser affected in increasing the compressor stable flow rage. The figure shows at flow rate coefficients of $0.0829,0.07554$, and 0.0637 , the compressor ran stably with the pinched diffuser of $\mathrm{b} / \mathrm{bp}$ 0.98 , while and at the same flow rates the compressor ran unstable with pinched diffuser of $\mathrm{b} / \mathrm{bp}$ of 1 . 
Figure 10 shows the compressor with a pinched diffuser of $b / b p$ of 0.98 has moved the surge point to very low flow rates with an improvement of $20.8 \%$. The enhancement in surge point is due to increasing the radial velocity that leads to suppressing instabilities in the diffuser. Also, maybe due to delay the rotating stall and hence the system surge. On the other hand, the pressure losses are due to increases in friction losses and dissipation of the radial velocity in the volute. However, the increase in surge point at low flow rates is accompanied by a high-pressure drop at high flow rates. These laboratory results are in agreement with the results published by Yohan [24] in the same effect of clearance on the compressor range of stable operation, despite the current compressor being a vaned diffuser and the other being vaneless. While experimentally, Ahti [25] found with vaneless diffuser compressor that the best design is a width ratio of 0.854 .

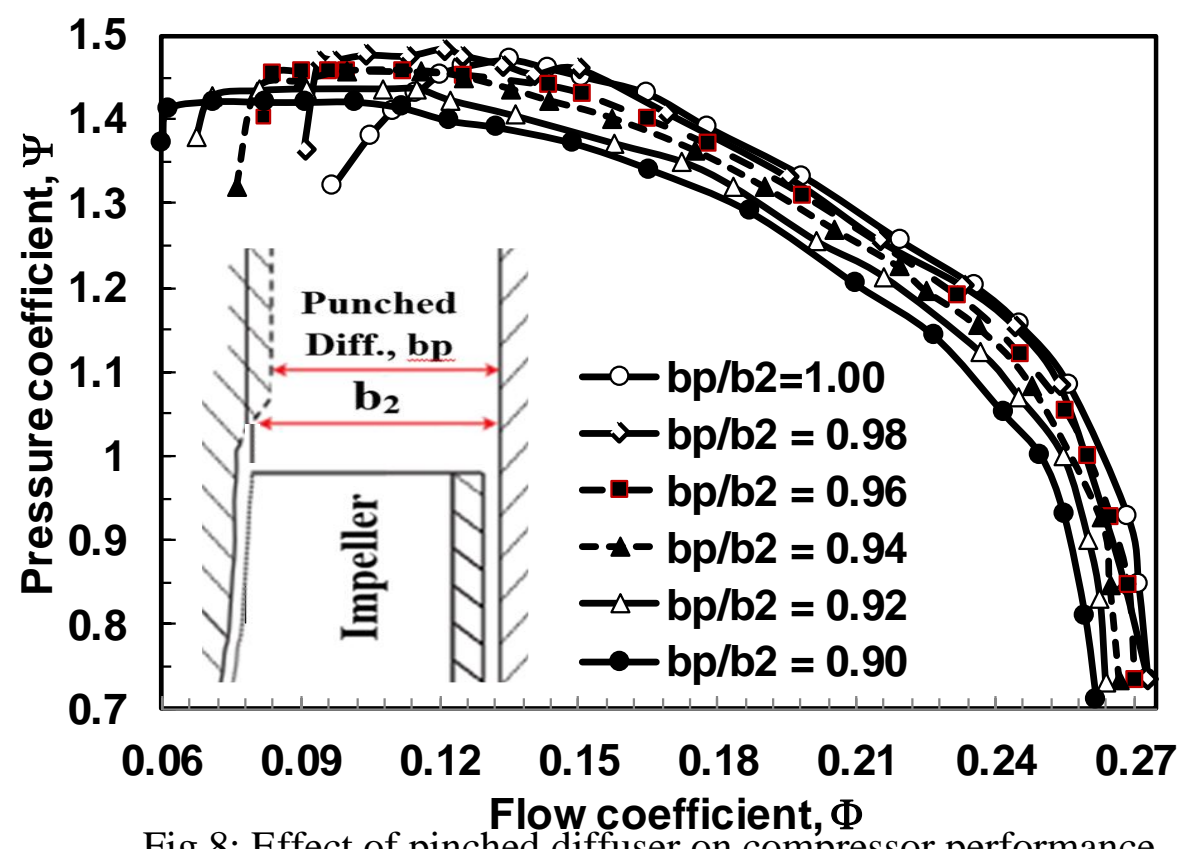

\section{Conclusions}

There are various published works that studied the effect of some volute design parameters on the compressor performance and efficiency, but few addressed the effects on the range of stable operations like rotating stall initiation, surge triggering, chocking, and compressor limit of stable operation. No previous trails were given on the effects of volute design on initiation of the rotating stall, surge, and range of stable operation. Different volute casing design parameters were investigated for increasing the compressor operating range without sacrificing the compressor pressure rise or efficiency. The present paper focused on the effect of volute casing surface roughness, axial and radial distance (clearance) between the impeller and diffuser volute casing, and vanes on reducing the unsteady phenomena due to stall initiation and surge beside the classical compressor characteristic of pressure rise coefficient, pressure recovery factor. The application of surface roughness of $100 \mathrm{~mm}$ increased the operating range of surge margin by about $10.9 \%$ due to controlling flow separation and flow recirculation effects. But when the surface roughness is greater than $100 \square \mathrm{m}$, viscous shear stresses lead to deterioration of performance and increase the percentage of decrease in tangential velocity, and thus increase frictional losses that lead to deterioration of centrifugal compressor performance. 


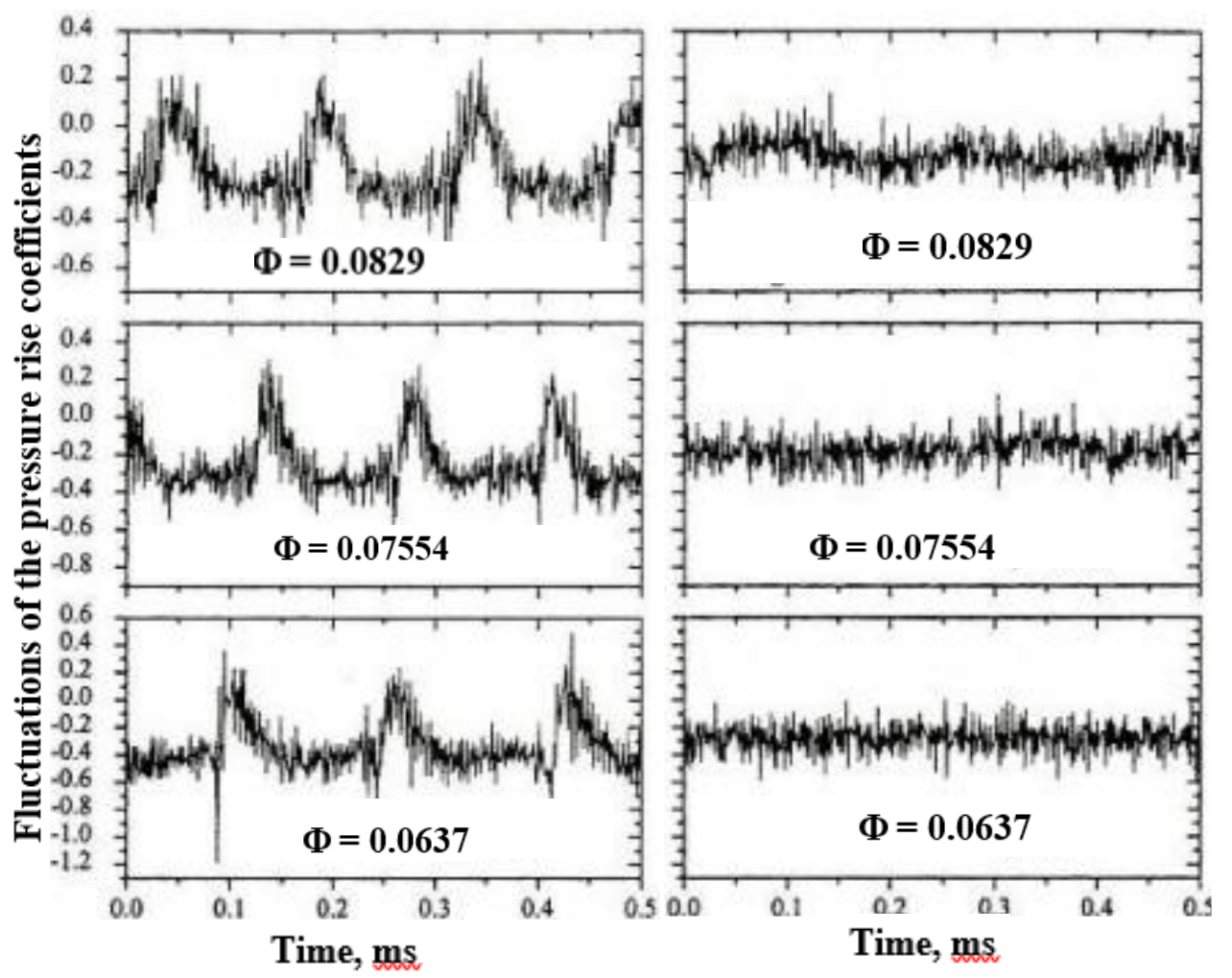

Fig.9: Fluctuations of the pressure coeffi. with diff. pinched diffuser of $b / b_{2}=1$ and 0.98 .

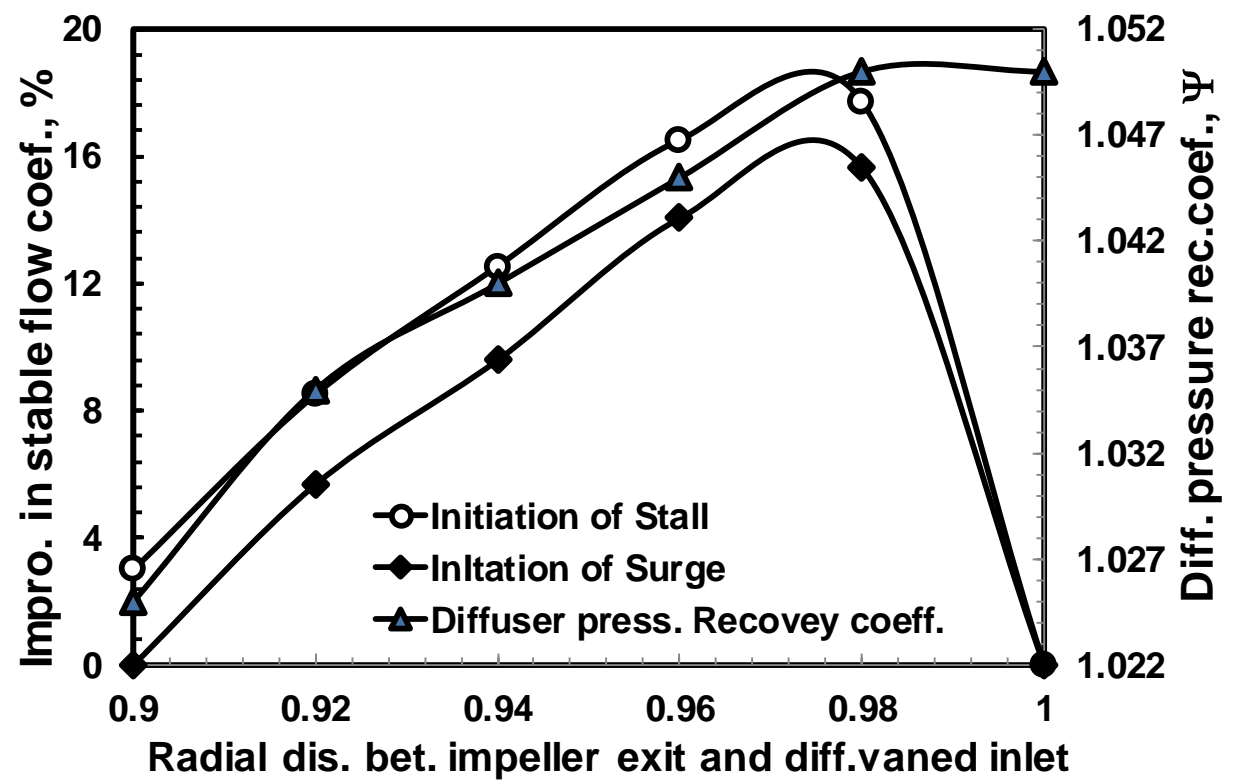

Fig.10: Improve in stable operating flow and diffuser pressure recov. coeff. with diff. pinched diffuser.

Effect of the axial clearance between the diffuser vanes and the casing of $\mathrm{C} / \mathrm{b} 2=1.2,2.4 \%$, $3.6 \%, 4.8 \%$, and $6 \%$ on the compressor stability was investigated. The best design of the axial distance between the diffuser vanes and the casing is $2.4 \%$ relative to the impeller exit blade height. And the compressor in this design gives about $12.4 \%$ improvements in the stable working range. The radial 
distance from the impeller blade exit to the diffuser vane inlet in (vaneless space radius) in six steps as $\mathrm{C} / \mathrm{r}_{2}=1.03,1.05,1.07,1.09,1.11$, and 1.13 relatives to the rotor outlet radius. The compressor with the radial vaneless distance of 1.056 gives improvements of about $16.6 \%$ in the surge margin, $2 \%$ in the pressure recovery, and $4 \%$ in pressure rise coefficients. The compressor has been tested with different pinched vaned diffuser distances relative to the impeller exit width of $b p / b_{2}=1,0.98,0.96,0.94,0.92$, and 0.9. It is very clear in the figure that the range of stable mass flow rate of the compressor increases as the pinched diffuser depth increases. The compressor with a pinched diffuser of $\mathrm{b} / \mathrm{bp}$ of 0.98 has moved the surge point to very low flow rates with an improvement of $20.8 \%$.

\section{References}

1. Amjid K., Muhammad I., Usama M., Mohammed J., Adam G., and Mohammad K., "Centrifugal Compressor Stall Control by the Application of Engineered Surface Roughness on Diffuser Shroud Using Numerical Simulations", https:// doi.org/10.3390/ma14082033, 2021.

2. Rajabpour S., Hajilouy B., and Manzari M., "Theoretical and experimental investigation of design parameter effects on the slip phenomenon and performance of a centrifugal compressor", Scientia Iranica, Transactions B: Mechanical Engineering 28, pp.291-304, 2021.

3. Xue, X., Wang, T., Zhang, T., and Yang, B., "Mechanism of stall and surge in a centrifugal compressor with a variable vaned diffuser". Chin. J. Aeronaut., 31, 1222-1231, 2018.

4. Mathew, D., and Farshid, S., "Investigation of Turbocharger Dynamics Using a Combined Explicit Finite and Discrete Element Method Rotor-Cartridge Model", J. Tribol., 139, 1-8, 2016.

5. Simpson, R.L. "A generalized correlation of roughness density effects on the turbulent boundary layer", AIAA J., 11, 242-244, 1973.

6. Cep, R., Jan, A., Petr, J., Sadilek, M., Mohyla, P., Valí, J., and Harni, M., “A. Surface Roughness after Machining and Influence of Feed Rate on Process", Key Eng. Mater., 581, 341-347, 2013.

7. Ceyrowsky T., Hildebrandt, A. and Schwarze R., "A New method for Assessing volute induced circumferential pressure distortion at the exit of a centrifugal impeller", Proc. of $13^{\text {th }}$ European Conf. on Turbo. Fluid dynamics \& Thermodyn. ETC13, Lausanne, Switzerland April 8-12, 2019.

8. Zhenzhong S., Xinqian Z., Zelin L., Tomoki K., Hideaki T. and Baotong W., "Influence of volute design on flow field distortion and flow stability of turbocharger centrifugal compressors", Proc. IMechE Part D: J. Automobile Engineering, IMechE 2018.

9. Dumitrescu O., Fetea G., and Gherman B., "Influence of the volute design on performances of a centrifugal compressor", IEEE: https:/www.researchgate.net/publication/321400403978-1-53863943-6, Nov. 2018.

10. Xinqian Z., Zhenzhong S., Tomoki K., and Hideaki T., "Experimental investigation of surge and stall in a turbocharger centrifugal compressor with a vaned diffuser", Elsevier, Experimental Thermal and Fluid Science 82, 493-506, 2017.

11. Mohtar H., Chesse P., Chalet D., Hetet F. and Yammine A., "Effect of Diffuser and Volute on Turbocharger Centrifugal Compressor Stability and Performance: Experimental Study", Oil \& Gas Science and Technology - Rev. IFP Energies nouvelles, Vol. 66, No. 5, pp. 779-790, 2011.

12. Xiaofeng S., Dakun S., Xiaohua L., Weiwei Y., and Xiaoyu W., "Theory of Compressor Stability Enhancement Using Novel Casing Treatment, Part I: Methodology”, Journal of Propulsion and Power, Volume 30, Number 5, Sep. 2014.

13. Stephanie W., Ivor D., Chris F., "Self-Regulating Casing Treatment for Axial Compressor Stability Enhancement”, ASME J. Turbomachinery, Volume 7, Parts A, SBN: 978-0-7918-5467-9, 2011. 
14. Ziegler, K., Gallus, H., Niehuis, R., "Study on Impeller-Diffuser Interaction-Part II: Detailed Flow Analysis", J.,125, 183, Turbomachinery, 2003.

15. Sato, K., He, L., "A Numerical Study on Performances of Centrifugal Compressor Stages with Different Radial Gaps", In Proceedings of the ASME Turbo Expo 2000.

16. Jaatinen A., Turunen T., Backman J.," The tip clearance effects on the centrifugal compressor vaneless diffuser flow fields at off-design conditions", Proc. of $10^{\text {th }}$ Eur. Conf. Turbomachinery Fluid dynamics \& Thermodynamics ETC10, Lappeenranta, Finland, April 15-19, 2013.

17. Ahmed S. Hassan, "Influence of the Volute Design Parameters on The Performance of a Centrifugal Compressor of an Aircraft Turbocharger”, Proc. IMechE Vol. 221 Part A: J. P. and Energy, 2007.

18. Behnam H. , Joao A., and Bijan F., Study of Tip Clearance-Casing Treatment on Performance and Stability of a Transonic Axial Compressor", ASME, J. Turbomach., Vol. 126, Issue 4, Oct. 2004.

19. Matthew F., "Experimental and Numerical Investigation of Tip Clearance Effects in a High-Speed Centrifugal Compressor", A Master Thesis, School of Aeronautics and Astronautics West Lafayette, Indiana Aug., 2020.

20. Japikse, D. "Advanced diffusion levels in turbocharger compressors and component matching", IMEC C45/82 (Concepts ETI, Inc., Vermont, USA), 1982.

21. Mohammad H., Zhenzhong S., and Xinqian Z., "Effects of Radial Gap Ratio between Impeller and Vaned Diffuser on Performance of Centrifugal Compressors", doi:10.3390/app7070728, J. Appl. Sci, 7, 728, 2017.

22. Mojaddam M., Hajilouy A., and Movahhedy M., "Experimental and numerical investigation of radial Flow compressor volute shape effects in characteristics and circumferential pressure nonuniformity", Scientia Iranica, Transactions B: Mechanical Engineering 20, 1753-1764, 2013.

23. Swamy M., and Pandurangadu V., "Tip Clearance Effects on Performance of a Centrifugal Compressor", Int. J. of Sc. \& Engineering Res., ISSN 2229-5518, Volume 5, Issue 1, January-2014.

24. Yohan J., Minsuk C., Seonghwan O., and Jehyun B.," Effects of a Nonuniform Tip Clearance Profile on the Performance and Flow Field in a Centrifugal Compressor", Int. J. of Rotating Machinery, Volume 2012, Article ID 340439, 11 pages, doi:10.1155/340439, 2012.

25. Ahti J., Aki G., Teemu T., and Pekka R., "Effect of Vaneless Diffuser Width on the Overall Performance of a Centrifugal Compressor" Proc. of the Institution of Mech. Eng., Part A: J. of Power and Energy, 2007. 